\title{
Notes on the vocalizations of Hill Blue-flycatcher (Cyornis banyumas)
}

Peter Boesman

In the following we briefly analyze and compare voice of the different races of Hill Blueflycatcher (Cyornis banyumas). We also try to quantify the extent of any vocal differences using the criteria proposed by Tobias et al. (2010), as a support for taxonomic review. We have made use of sound recordings available on-line from Xeno Canto (XC).

We are especially interested in comparing the morphologically distinct race magnirostris (breeding in the eastern Himalayas) with other races.

The Ripley guide (2nd ed., Rasmussen \& Anderton 2012) describes voice of magnirostris as unknown. XC has however some recent recordings (of presumably this taxon) from two sites: (all recorded in May, Himalayas, India).

Some examples illustrated with sonograms:

magnirostris
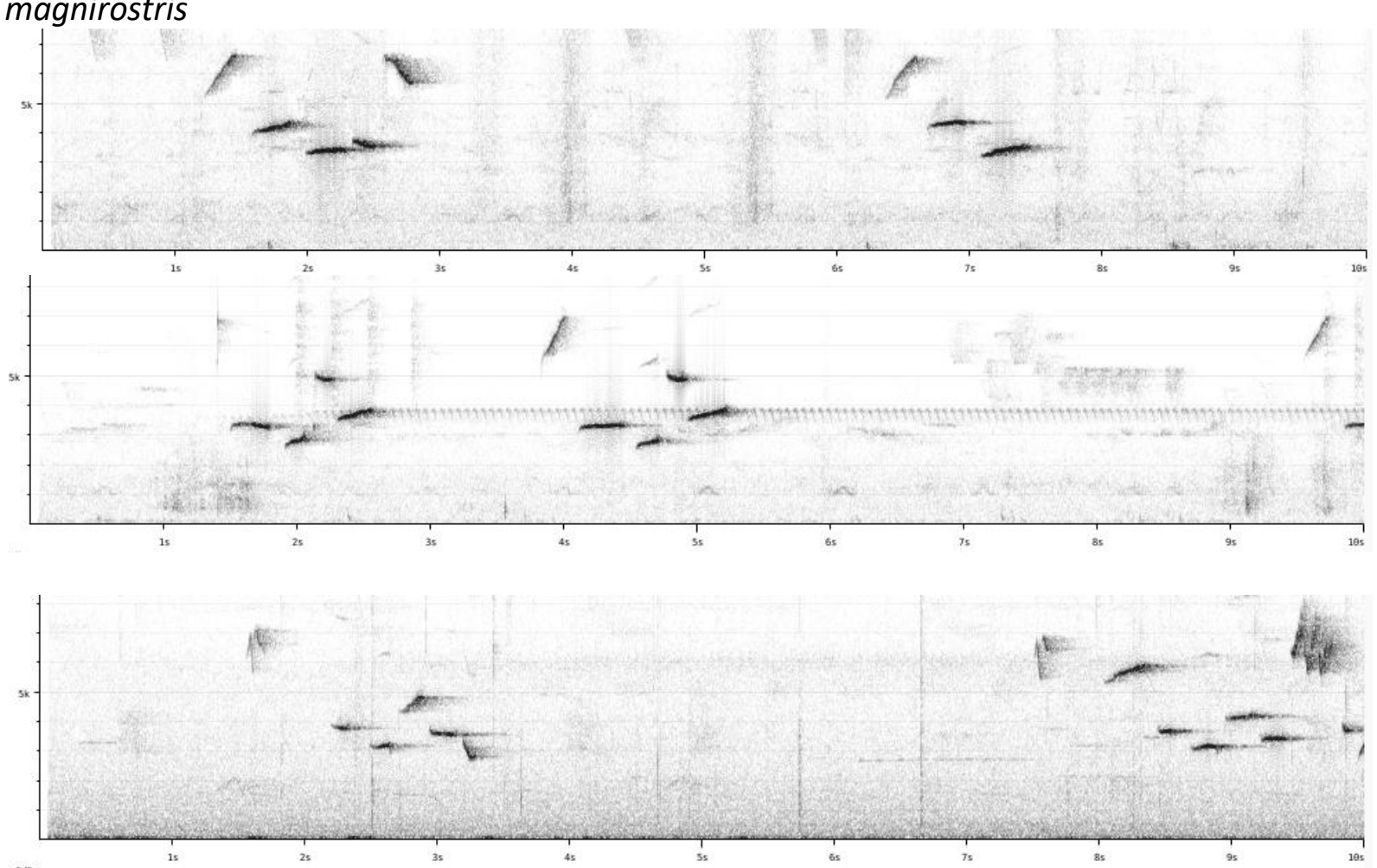

(There are also a few recordings from S Thailand in February of singing birds, these may be birds practicing song in their wintering area. Song is rather similar to above, with some additional harsh call notes.) 


\section{HANDBOOK OF THE \\ Alve}

Comparison with other races:

$\mathrm{N}$ Thailand

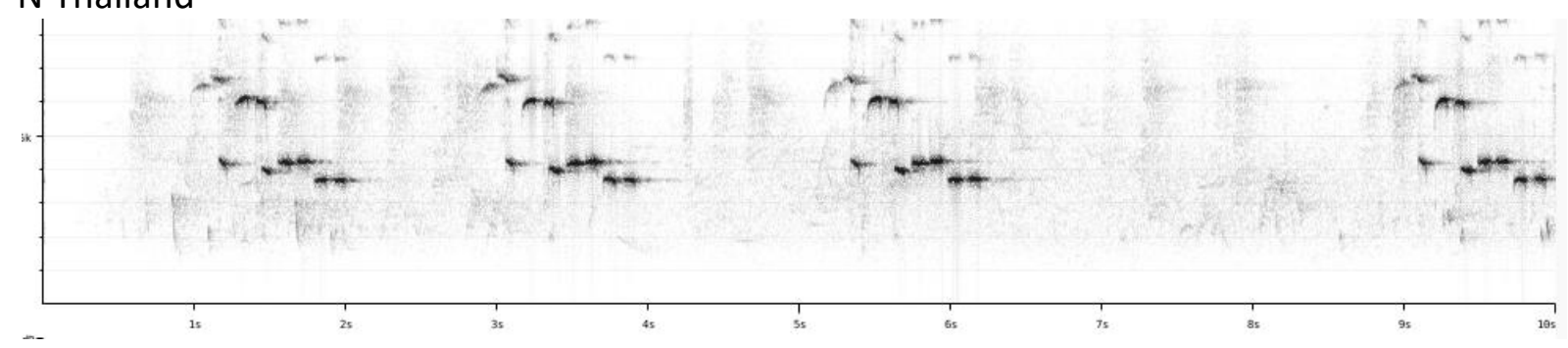

\section{China}

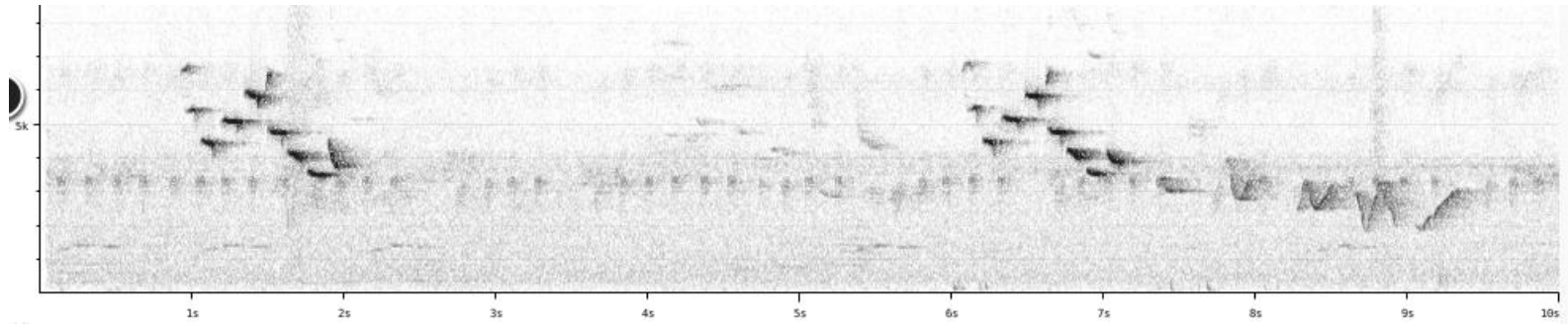

\section{Peninsular Malaysia}

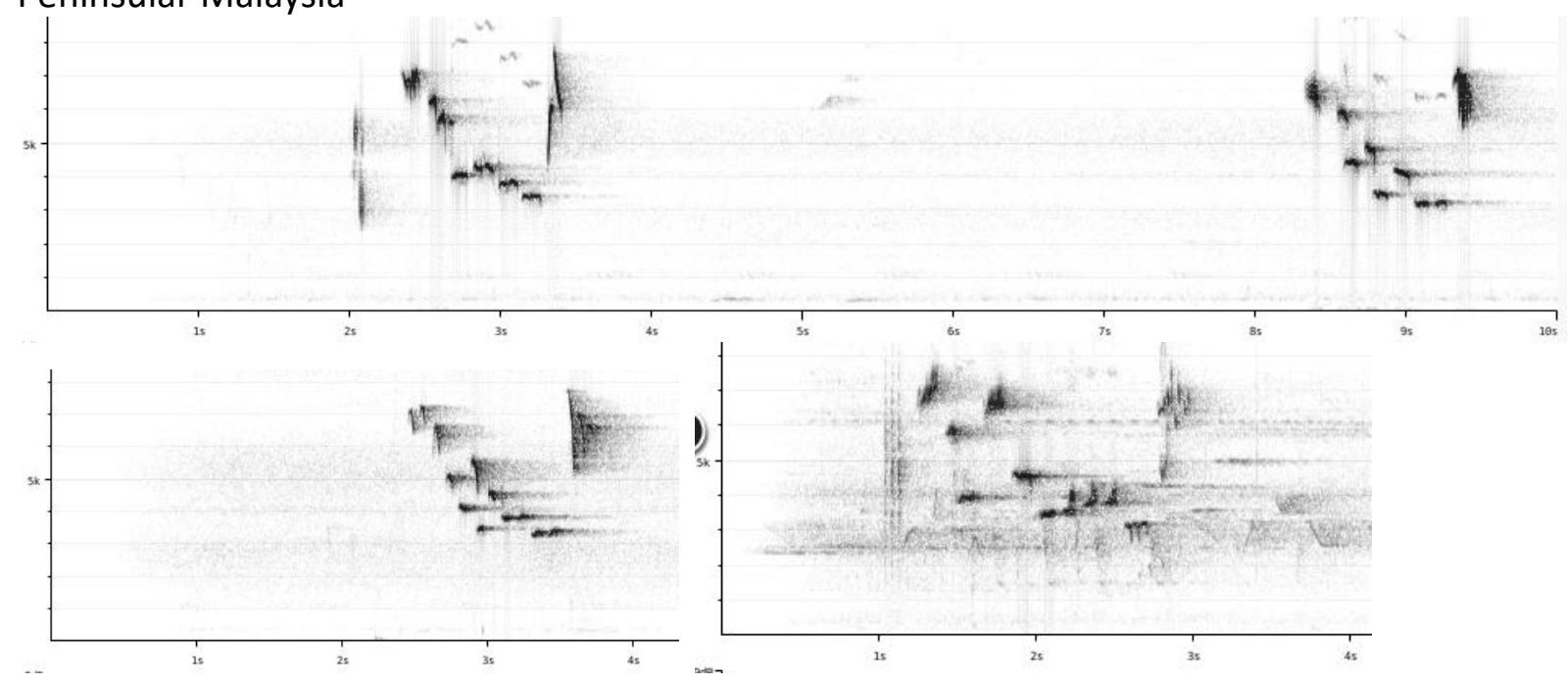

\section{Vietnam}

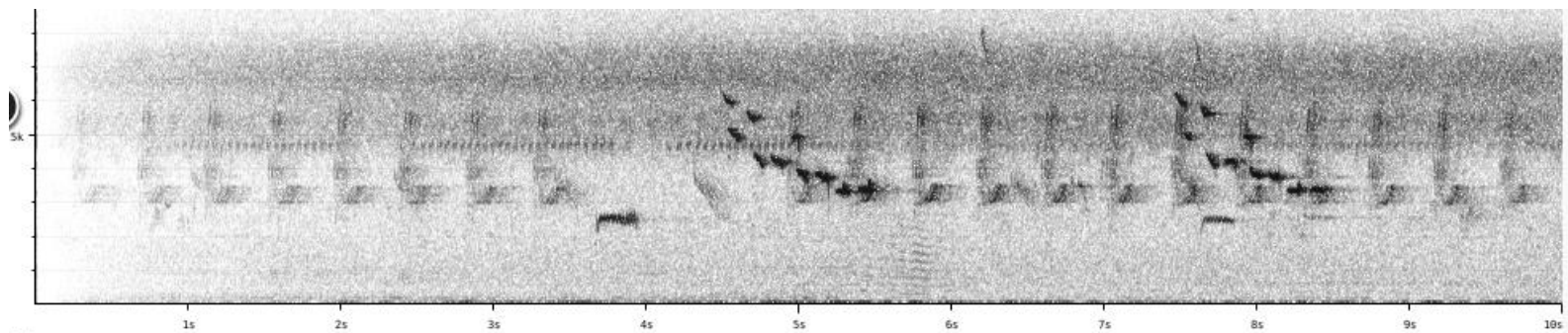

Java
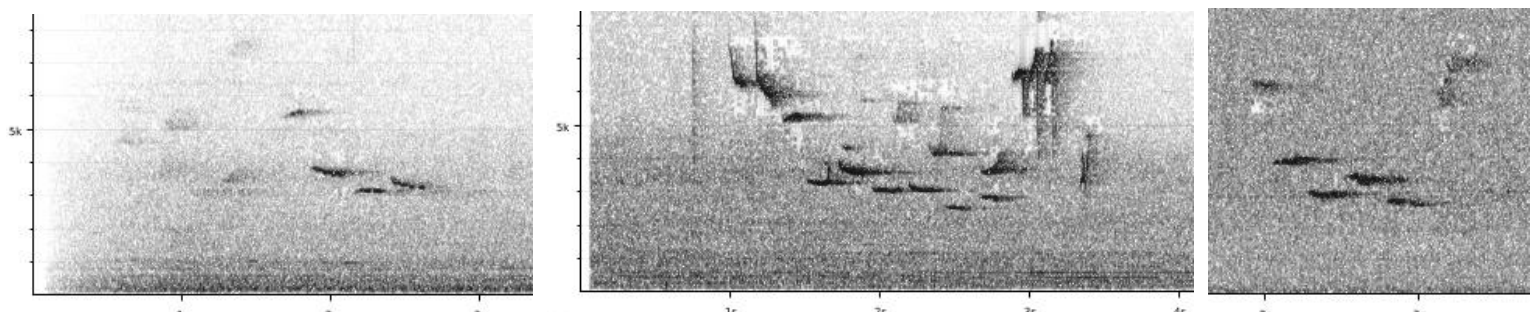

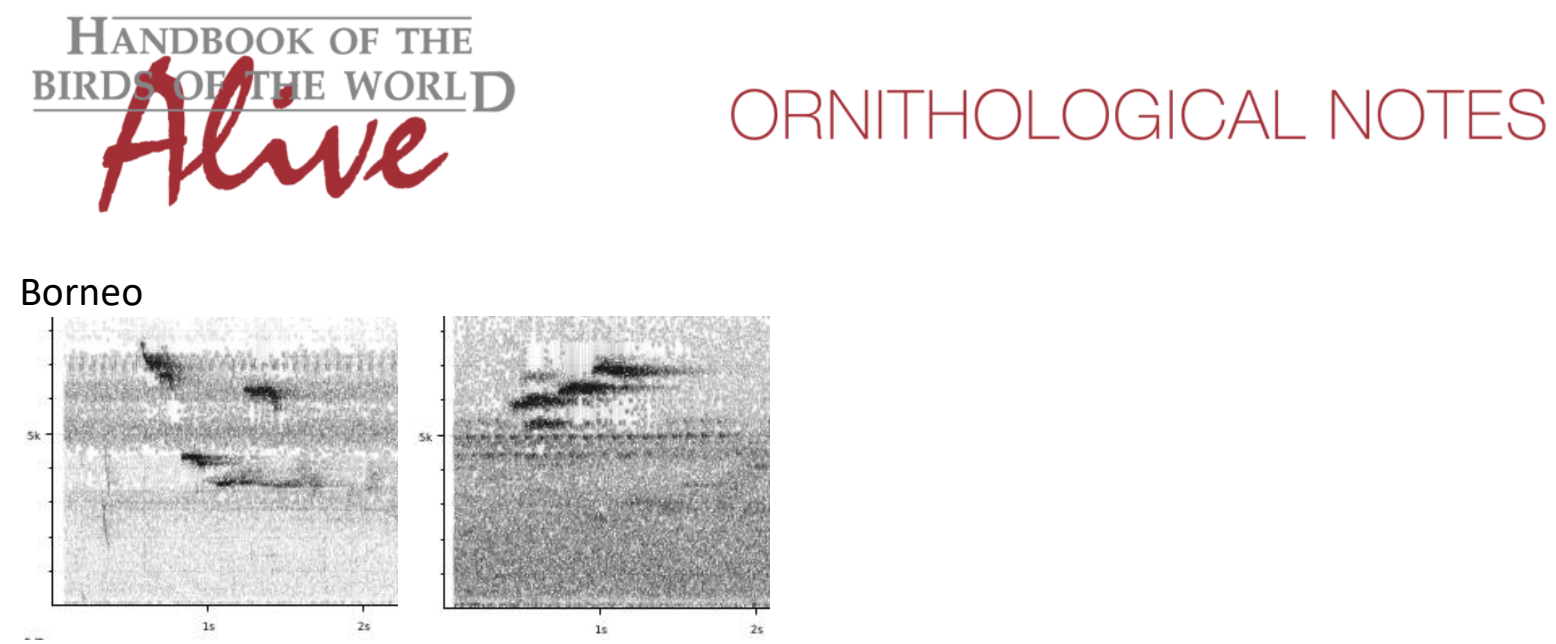

It would seem that song of magnirostris is clearly different from other races on the mainland, the latter typically having many more shorter notes per song phrase.

On the other hand, recordings from Java (banyumas) and Borneo (montanus) are apparently closer to magnirostris (less \# of notes which are longer and have flatter pitch).

If given a vocal score, this would be fairly high for magnirostris vs. mainland races based on lower number of notes in a song phrase (2-3) and notes having a longer duration (2), but much less so vs. the two island races, as the few available recordings don't show significant vocal differences in the latter case.

An additional note of caution: one should also take into account that birds may utter both a full song and a short song (HBW Alive: Clement 2016). While it would be quite a coincidence that the recordings of the Himalayas and the islands are only of the short songs, it further complicates the case. There are a few recordings from the mainland which show such a short song but these seem to be rather exceptions. An example from Laos:

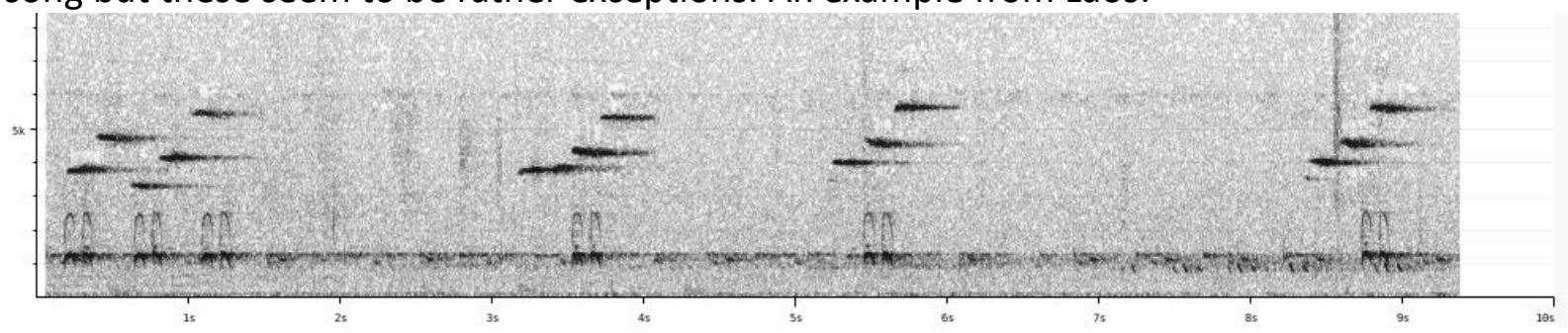

We can thus conclude that magnirostris, banyumas and montanus seem vocally distinct from other races, but to get a better understanding of the range of variation, more recordings are needed.

This note was finalized on 6th May 2016, using sound recordings available on-line at that moment. We would like to thank the many sound recordists who placed their recordings for this species on XC, and in particular Pritam Baruah, Peter Ericsson and Soenke Tautz, for recordings of magnirostris.

\section{References}

Clement, P. (2016). Hill Blue-flycatcher (Cyornis banyumas). In: del Hoyo, J., Elliott, A., Sargatal, J., Christie, D.A. \& de Juana, E. (eds.). Handbook of the Birds of the World Alive. Lynx Edicions, Barcelona. (retrieved from http://www.hbw.com/node/59089 on 6 May 2016). 
Tobias, J.A., Seddon, N., Spottiswoode, C.N., Pilgrim, J.D., Fishpool, L.D.C. \& Collar, N.J. (2010). Quantitative criteria for species delimitation. Ibis 152(4): 724-746.

\section{Recommended citation}

Boesman, P. (2016). Notes on the vocalizations of Hill Blue-flycatcher (Cyornis banyumas). HBW Alive Ornithological Note 315. In: Handbook of the Birds of the World Alive. Lynx Edicions, Barcelona. (retrieved from http://www.hbw.com/node/1251849 on 18 October 2016). 